\title{
TITLE:
}

\section{$<$ Note $>$ Snare removal by a chimpanzee of the Sonso community, Budongo Forest (Uganda)}

\section{$\operatorname{AUTHOR}(S)$ :}

Amati, Stephen; Babweteera, Fred; Wittig, Roman $\mathrm{M}$

\section{CITATION:}

Amati, Stephen ...[et al]. < Note> Snare removal by a chimpanzee of the Sonso community, Budongo Forest (Uganda). Pan Africa News 2008, 15(1): 6-8

\section{ISSUE DATE:}

2008-06

URL:

http://hdl.handle.net/2433/143488

\section{RIGHT:}

Copyright (c) Pan Africa News. 


\section{<NOTE>}

\section{Snare removal by a chimpanzee of the Sonso community, Budongo Forest (Uganda)}

Stephen Amati, Fred Babweteera, Roman M Wittig

Budongo Conservation Field Station (BCFS)

P.O. Box 362, Masindi, Uganda

Email: bfp@utlonline.co.ug

Hunting is one of the biggest threats to the survival of our closest living relative, the chimpanzee. While chimpanzees in West ad Central Africa commonly get directly shot by hunters and subsequently end up on the bushmeat market (see: www.wildchimps.org), the effects of hunting on chimpanzees in East Africa are more indirect. Hunters put up wire snares in the forests of East Africa in order to catch duikers and bush pigs. However, often snares catch other animals, such as chimpanzees. Their hands or feet get caught in the snares, causing subsequent loss of limbs or mutilation of hands and feet $^{1,2,3}$.

In the Budongo Forest, in western Uganda, snaring is the traditional way to provide animal protein for one's family. The snare removal team of the Budongo Conservation Forest Station removes snares from the forest since January 2000 (further details see 4). During the three years, from 2005 to 2007, BCFS staff removed on average about 220 snares per month from Budongo Forest. Nonetheless snaring injuries are frequent in our habituated chimpanzee community at Sonso. During the last year we had three new incidences of snared individuals. As a result about $30 \%$ of the adults from the Sonso community show permanent mutilation related to snares (see Fig. 1).

When a chimpanzee gets caught with its hand or foot in a snare, it usually pulls as long as the snare is still attached to a branch or sapling. During this process the wire of the snare cuts deep into the flesh and the snare 


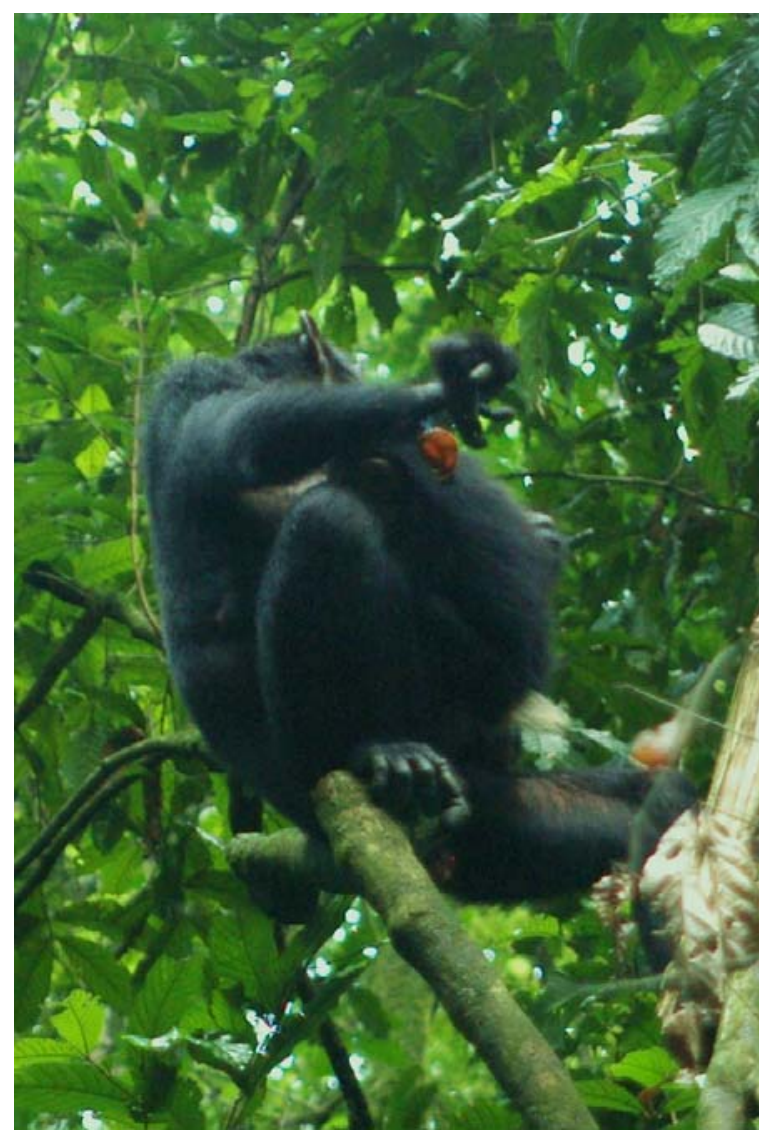

Fig. 1. Female Kewaya with her daughter Kox. Kewaya's right hand got caught presumably in a snare before 1992 (when continuous observation in Sonso started) and degenerated to an immobile hook at the end of her right arm (photo by Roman Wittig).

starts to stop the blood circulating in the limb. If the snare is not removed within days it will cause permanent damage to or loss of the limb. In the long run disadvantages during feeding ${ }^{2}$ or lethal infections ${ }^{5}$ are common due to the snares. Removing the snare, however, is not easy. It involves anesthetizing the chimpanzee without others being around, and may be dangerous for the chimpanzee itself ${ }^{6}$. Only 1 attempt of 3 was successful in anesthetizing a chimpanzee by darting in Budongo.

Here we report an observation in which a chimpanzee helped to remove the snare from another individual:

'On January 18, 2008, at 16:45h a party of 27 chimpanzees was traveling through the Budongo Forest. They had been feeding during the afternoon and were on their way to their nesting area. At 16:53h female Kwera (adult female, estimated age of 27 years) started to scream without an obvious reason. Her family and other party members started also scream and alarm calling. A closer look revealed that Kwera's right hand was caught in a nylon snare attached to a little tree sapling. A couple of minutes later the alpha male Nick (adult male, estimated age 26 years) arrived and displayed at Kwera, who was immobilized. After hitting Kwera a couple of times, Nick stopped and sat next to her. Nick broke off the small sapling so that Kwera was able to move again. However, the snare was still around her hand, which was still attached to a stick of about $30 \mathrm{~cm}$.

The party continued traveling towards the South. At 17:18h the party started to move through an area of thick undergrowth, quite common in Budongo Forest. The stick attached to Kwera's snare got stuck between the little trees. Again she started to scream while pulling on the snare. Nick came back and displayed again towards her. He pulled on the stick, which made Kwera scream more. Kwera presented to him and Nick started grooming her. While being groomed, Kwera manipulated the snare with her teeth trying to bite through the nylon string. After a five minutes Nick took Kwera's right arm, held it up and investigated the snare. He started to manipulate the nylon with his teeth while holding Kwera's arm and the stick firmly in position. After a few minutes the snare fell off and the party continued moving towards block BA close to BCFS.'

A closer look at the snare showed bite marks on the nylon and a cut through. The piece of nylon string and the remaining stick was brought to camp. We concluded that Nick had bitten through the nylon and freed Kwera from the snare.

This is the first time that we observed a chimpanzee removing a snare from another individual. In this light the sudden disappearance of snares within days after the individuals got trapped may indicate active snare removal. Three cases have been reported within the Sonso community: 
1. On January 31, 2008, Monica, an infant of Melissa, was caught in a snare at her left hand. Four days later, on February 4, she was seen without the snare.

2. On June 13, 2006, Kasigwa, an infant of Kutu, was seen with a blue nylon snare on her right foot. The snare had disappeared two weeks later.

3. In February 2003 Kana, at this time an infant of Kutu, was seen with a snare injury mark at her right ankle. The injury was still bleeding. The snare, however, had disappeared already.

Although there was no direct observation, active snare removal might have happened in those cases. Usually snares, once they have been pulled off the sapling where they are attached to, have cut deeply into the flesh and will fall off only when the material has disintegrated. Often individuals carry their snares for months before the wire has corroded enough to break, while nylon is known not to disintegrate at all.

Another striking point was the close investigation and careful removal of the snare by Nick. It did not only remove the snare but he kept Kwera's arm in position so that she couldn't hurt herself. It remains unclear whether Nick's behavior was triggered by an ad-hoc stimulus enhancement (or any other low-level social learning process), following Kwera's example, or he understood the reason for the problem. In a community where many chimpanzees have self-experience with snares it seems possible that individuals may make the connection between the snare and the screaming involved. Experience may allow them to remove a snare.

However, this was a one-off chance observation and whether similar events have happened beforehand (as suggested above) is purely speculative. We need more direct observations from the Sonso and other communities. Therefore we would like to ask other researches from other study sites to contact us when they have made similar observations (as for example reported from Taï, Côte d'Ivoire: page 34 in 5).

Acknowledgments: We thank the Office of the President of Uganda and the Ugandan Authorities (National Forest Authority and Uganda Wildlife Authority) for their permission to conduct research on the chimpanzees of the Budongo Forest. We are grateful to Lucy Bates, Monday Gideon and James Kakura for their helpful observations, to Vernon Reynolds and Klaus Zuberbuehler for their comments on the manuscript and to the Royal Zoological Society of Scotland for their financial support of the Budongo Conservation Forest Station.

\section{REFERENCES:}

1 Hashimoto C 1999. Snare injuries of the chimpanzees in the Kalinzu Forest, Uganda. Pan Afr News 6:20-22.

2 Waller JC, Reynolds V 2001. Limb injuries resulting from snares and traps in chimpanzees (Pan troglodytes schweinfurthii) of the Budongo Forest, Uganda. Primates 42:135-139.

3 Wrangham RW, Mugume S 2000. Snare removal program in Kibale National Park: a preliminary report. Pan Afr News 7:20-22.

4 Reynolds V 2005. The Chimpanzees of the Budongo Forest: Ecology, Behaviour, and Conservation. Oxford University Press, Oxford.

5 Boesch C, Boesch-Achermann H 2000. The Chimpanzees of the Taï Forest : Behavioural Ecology and Evolution. Oxford University Press, Oxford.

6 Suzuki A 1972. On the problems of conservation of the chimpanzees in East Africa and of the preservation of their environment. Primates 12:415-418. 